\title{
Productive Protection of Intangible Cultural Heritage Based on the Theory of Involvement: A Case Study on the Farmers' Paintings of Xin- Ji County, Hebei Province, China
}

\author{
Kong Xuhong ${ }^{1 *}$, Hong Jingjing ${ }^{2}$ \\ 1,2 Management College, Hebei University, Baoding, Hebei Province, PRC, 071002
}

\begin{abstract}
The productive protection of intangible cultural heritages, always in the form of tourism development under the present context, is put forward by Chinese scholars, which are beneficial to both the protection of the heritage and the economy development of the locals. While not all intangible cultural heritages can be understood and accepted by tourists due to the reasons that the living circumstances and contexts of these heritages are changing and disappearing that it's hard for tourists to understand, neither do they desire to pay for it. Therefore, how to make tourists even including some craftsmen understand and accept the heritage means a lot to the protection and inheritance of these heritages. The paper argues that the Involvement Theory can be referred to analyze settle the problems. A case study of the farmers' painting in Xinji County, Hebei Province was carried out as the example, which is one of the most representative intangible cultural heritage of folk art in Hebei Province, China, with a long history of development, rich cultural connotation and high artistic value. A field investigation and deep-interview was carried out to gather the information of its status quo, problems of its inheriting and developing were analyzed, the paper found that with the development of the times and society, farmers' painting is losing its survival environment, the income of farmers' painting is not proportional to their putting-in and cost, the value of farmers painting can not be reflected, and the productive protection is seriously hindered. Therefore, based on the perspective of involvement theory, this study analyzed the bottleneck of productive protection of Xinji Farmers' Painting, suggested how to stimulate the involvement of tourists into the understanding and producing and creation of the paintings in order to promote the inheritance of the heritage.
\end{abstract}

Key words:Xinji Farmers' Painting; involvement Theory; Productive Protection; Intangible Cultural Heritage

\section{Introduction}

Intangible cultural heritage is our spiritual home left by our ancestors, playing more and more important roles in cultural recognition, economic development and rural revitalization. Tapping the intangible cultural resources is becoming a key way to

\footnotetext{
* Author: Kong Xuhong(1973-), Ph.D and Professor, specialized in tourist resource and rural development. E-mail: kongxuhong@126.com mobile:+8613831268236
} 
reestablish local economy and develop local industry. The productive protection theory and practice is initiated by Chinese scholars. Due to its obvious value in tourism and economic development, the commercial utilization of intangible cultural heritage, usually in the form of tourism development, has been paid full attention these years. In order to avoid excessive commercialization and to differentiate it from the protection under the governmental financial sponsor and solve the dilemma of government protection, Wang (2006) initially put forward this concept in his book, introduced the idea of productive protection of intangible cultural heritage and pointed out that productive protection is one of the basic ways and principles of intangible cultural heritage protection.

While the productive protection is welcomed and practiced by craftsmen, not all intangible cultural heritage can be understood and accepted by tourists due to the reasons that the circumstances and contexts have changed a lot, it is hard for tourists to understand the spiritual contents of the heritage and why it is should be in that way, they are reluctant to pay for it. Therefore, how to motivate craftsmen manifest the art value, regional or ethnic cultural connotation and times background, make tourists understand and accept the heritage means a lot to the protection and inheritance of these heritages. The paper suggests that the involvement theory can be referential to the analysis and settlement of these problems, and a case study was carried out to analyze the dilemma the intangible cultural heritage confronting and how involvement theory can be used under this circumstance.

\section{Research Review}

\subsection{Relevant Research on Productive Protection}

The concept of productive protection of intangible cultural heritage was first put forward by Wang Wenzhang in 2006 in his book, where he argues that productive protection is one of the basic ways and principles of intangible cultural heritage protection. This was followed by the definition given in the Guidance on Strengthening the Productive Protection of Intangible Cultural Heritage which was formally formulated and issued by the Ministry of Culture of China in February 2012, therein said that "productive protection of intangible cultural heritage refers to the maintenance of the authenticity, integrity and inheritance of intangible cultural heritage in the course of practice of a productive nature, on the premise of effectively inheriting the skills of intangible cultural heritage, with the help of production, circulation, sales and other means, the intangible cultural heritage and its resources are transformed into the protection of cultural products." The protection consciousness and cultural consciousness of the inheritors can be effectively enhanced and the economical benefits can be created to the relative stakeholders by the productive protection and conversion of intangible cultural heritage resources into cultural products (Liu Xiaochun et al., 2016). By taking into account economic benefits and cultural spirit, inherits and develops, productive protection has become a hot topic in the field of intangible cultural heritage study, achieved good effects and influence in the field of traditional skills, traditional fine arts and traditional medicine processing.

While more people recognized productive protection as a kind of a new approach to the protection of intangible cultural heritage, the implementation of productive protection is not as easy as their imagination, and the first is the question of the way of intangible cultural heritage innovation. With the fast pace of modernization and the urbanization, many intangible cultural heritage has been difficult to integrate into the life of the present generation, and how to make the modern consumers accept and understand the intangible heritage is a problem that needs to be solved urgently. There are a lot innovation practice in the field, such as the " $1+3+\mathrm{N}$ " endogenous dynamic mechanism in which, " 1 " refers 
to " a set of inheriting mechanism, " 3 " refers to three driving systems, " $N$ " means several inheriting carriers, this endogenous dynamic mechanism aims to stimulate the motive force of intangible cultural heritage to achieve the transmission of the external blood transfusion type into the power of blood generating type. The establishment and the good operation of the three driving systems (the conscious system, the motivation system and the social operation system) are the decisive force for the effective operation of the dynamic mechanism. It is directly applied to the intangible cultural heritage itself and the several inheritance carriers with a key and decisive function of promoting the productive protection of the intangible cultural heritage. (Chen J.X.2016). Some productive protection tries to build sacred consumption which means that only with "Gods, ancestors and ghost sacred consumption" the strong vitality and identity can be assured. In the process of protecting the traditional art, it is undoubtedly one of the effective ways to protect the traditional technology if it is introduced into the field of folk custom, belief and ceremony(Wen,2017). Liu(2012) suggested the studio inheritance mode of taking the quality route, the large-scale production imitating commercial development and the development of related derivatives, etc.

Secondly, when more people are generating the desire to buy, the question that needs to be further addressed is what channels should these heritages be sold through, including taking advantages of some new customs and festivals such as temple fairs, Valentine's Day, Christmas,etc.(Liu,2014) or selling through the display and exhibition in the meanwhile of producing in workshop (Yang,2016). A putting-out system can also be introduced, which is a kind of hand-made production mode the rural craftsmen and the buyers come to terms and cooperation in the aspects of capital, raw material supply and finished product sales, characterized by the informal contract and the dispersed production (Xu,2016).

Another problem productive protection method have to face lies in the authenticity of the intangible cultural heritage. The cultural connotation including the function, the generating background, the moral of the intangible cultural heritage should be paid attention to and protected and inherited in addition to the heritage itself and the process of production. How to make tourists understand, accept and approve the cultural contents is a significant problem concerning to the inheritance and widespread of the heritage. Based on the theory of involvement, the study tries to make some tentative analyse on the problems how to make tourists more involved and enhance their identity in the cultural heritage.

\subsection{Involvement Theory}

The concept of "involvement" was first put forward by Krugman (1965). He defined involvement as the connecting experience, connection, or the number of links built or recognized by audience between his own life and the stimulus in unit interval. From this definition, the substance of the involvement is a reflection of strong or weak relationship between the subject and the object. Since Krugman, a number of scholars have made a great deal of research on the involvement and have developed the involved concepts. Palanisamy and Wong(2003) defined involvement as the extent to which an stimulus or task is associated with the existing needs and ideals of the consumer. Zaichkowsky(1994) believes that involvement is the extent to which an individual perceives an advertisement or product associated with its inherent needs, life ideals and interests, while Laczniak,Muelhing and Grossbart(1989) pointed out that involvement is a state of individual motivation induced by a particular advertisement or situation.

In this study, involvement is understood as an unconscious experience, mainly referring to whether tourists feel the correlation between themselves and one of the factors of the intangible cultural heritage in need of productive protection. This is consistent with the fact that some traditional intangible cultural heritage can not be appreciated by tourists. Most of 
the research on involvement theory is applied in the field of marketing and pedagogy. Few scholars pay attention to the theory of involvement in the field of cultural heritage research, and have not yet discussed the productive protection of intangible cultural heritage from the perspective of involvement theory.

\section{Case Study on Farmers' Painting}

\subsection{Profile of the Farmers' Painting of Xinji}

\subsubsection{Historical Review of the Xinji Farmers' Painting}

Farmers' painting of Xinji County is one of the most representative intangible cultural heritage of folk art in Hebei Province, China, which is a reflection of farmers' life in different times with a very strong times color. During its long history of development, it has formed its own rich cultural connotation and high artistic value. As early as the Ming and Qing Dynasties, people here have folk traditions of painting, embroidery, cutting, weaving and so on. In the 1950s, the People's Art Publishing House had published two picture books about wall pictures of the county. In 1959, farmers' painting was exhibited in the Leipzig International Expo, Germany. In the 1960s and 1970s, the development of farmers paintings tended to be elegant and detailed, paying attention to shaping. A selection of amateur paintings by the masses was published.

During the Great Leap Forward Movement in 1958, Xinji people used cartoons and slogans to arouse the determination of the broad masses of people to actively fight against the enemy. Most of the farmers paintings at that time were based on the party's principles and policies, and also reflected a kind of revolutionary feelings. Most of the farmers' paintings in this stage are displayed in the form of wall paintings. Although the painting style is simple, most of them show the daily life of farmers, such as sowing, spring ploughing, fattening, harvesting and so on, they are vivid and powerful, which represents the farmers' yearning for socialist construction.

During the political movement of the Cultural Revolution, an extremely sensitive period, which was also a catastrophe for the art world, most of the art works at that time followed the party's principles and policies. Looking back at the Xinji farmers' paintings during the Great Revolution, it is not difficult to find that many of them are works with Mao Zedong as the theme. Although this period limited the expression of farmers painting works in the form and content too single, the painting level and color collocation have been significantly improved.

After the two turbulent periods of "Great Leap forward" and "Cultural Revolution", Xinji farmers' painting finally ushered in a period of free and open development. Farmers' painting in this period does not need to focus on political factors, but freely play their own imagination to creation. It was during this time under the leadership of Geng Zhanxiong that Xinji farmers' painting reached a new peak in the manifestation of the successfully held "Xinji Modern Folk painting Exhibition" at the National Art Museum of China on February 14, 1987, and the establishment of Wangxia Village Women Painting Society, which attracted the attention of the world because of its strong artistic flavor and strong folk art color. French embassy officials, British scholars, Mexican embassy officials in China came to Wang Xia Village to pay an exclusive visit to the female farmers' painting society and gave a high praise. 


\subsubsection{Artistic characteristics of Xinji Farmers' Painting}

Hebei Xinji farmers' painting is obviously different from other painting types in terms of painting content and painting method, which embodies the unique cultural characteristics. The inspiration of farmers' painting comes from the experience of farmers' daily production and life, covering a very rich theme, ingenious conception and a strong local cultural flavor, which has strong characteristics of nationality, folklore, originality and creativity, expresses the customs of rural areas and farmers. Xinji farmers' painting is rich in subject matter, ingenious in conception, unfettered, exquisite and simple in painting, and beautiful in color. With the simple lines, farmer's experience and vision of rural life are vividly and incisively expressed, from big life events such as spring ploughing and autumn harvest, weddings and funerals, to as small as a single brick and tile, trees and bushes, all exudes a strong local flavor and regional amorous feelings. In addition, it also absorbs the quintessence of paper-cut, printing and dyeing, opera and other arts, and integrates into the painting, forming a unique style of childish simplicity that suits both refined and popular tastes.

\subsection{The Problems of Productive Protection of Xinji Farmers' Painting}

Xinji farmers' painting was listed as an intangible cultural heritage representative of Hebei Province in 2006. Productive protection was adopted and a creation base was established. Farmers painting are becoming well-known and popular in the market.

While there are some problems existed in the productive protection of farmers' painting. Firstly, there is an imbalance of development between villages. In 2017, Wangxia Village was listed as a characteristic town featured painting creation which got a 6 million yuan investment, there are almost a hundred farmers painters between 30-50 years old. While in other villages, some painters left villages to work or do businesses in cities because the lack of sale, the left painters are aging seriously, the farmers' painting is losing successor.

Secondly, the painting is losing its creation roots. Farmers' painting is generally based on the productive labor of farmers or the simple scenery of rural areas, and the traditional folk villages are the creative environment of most farmer paintings. With the acceleration of urbanization in rural areas, the traditional farming life has undergone earth-shaking changes, the traditional folk villages have been destroyed, the artistic expression of traditional farming life and its memory and the source of materials for farmers painting is becoming deficient.

Thirdly, the painter is changing. The creator of farmers' painting is supposed to be a farmer, living the rural life of farming when he is busy and painting when he is idle. Painting is an amateur activity. As the myth of farmer painters getting rich became popular in painting villages, and farmers' painting has been used in specialty and souvenir producing, the painting derivatives are not only painted on paper, but also printed on umbrellas, cups, fans. It not only brought high reputation at home and abroad, but also real benefits for the local farmers. Now the painting has been accepted in educational system, more painters are becoming professional, some villages are changing to painting villages during the process of productive protection. The painters evolve to two different ends, one is the high-end pursuing of farmers' painting masters, the other is the low-end mass production and batch copy of the unnamed farmer painting workers.

Fourthly, the market is changing. The prosperity of farmers painting has its background, when there is not enough artist forms and entertainment. The farmers painting meets the aesthetic demands of market. With the continuous development of the times, the cultural life of the Chinese people is no longer scarce, and a variety of art forms emerged 
endlessly. Problems such as the old school of painting works are not in line with modern aesthetics, the form of expression is old-fashioned and can not meet the needs of modern individualization, the content of expression is solidified and different from the contemporary thought, and the historical value, cultural value and artistic value behind it are not well known to the public reduced the farmers painting were largely shrugged off by the market. As a result, a large number of old farmer painters put down their brushes. Now only Geng Zhanxiong and Wang Xiaojun as well as Cao Zhihua, Jia Yan and Geng Zhanxiong's daughter, Geng Wenxiao working in Xinji Cultural Museum are the only old artists who are still insisting on farmers' painting creation.

Other problems such as high enterprise tax burden, the lack of funds are also interfering with the protection and development of farmers' painting. The most important the problem is how to understand farmer's painting and how to make it accepted by market, whereby can be analyzed and solved by the involvement theory.

\subsection{Productive Protection Countermeasures of Xinji Farmers' Painting Based on Involvement Theory}

First of all, it is important to note that, while promoting its inheritance and development in the form of sales in the production protection, to meet the needs of modern people can not be avoided. But one main line must be stick to, that is, to always follow the core skill and core culture of the farmers' painting. As shown in Fig.1, both farmers and tourists need to be involved in the producing of the painting, while the experience type involvement, the exposure type involvement should be strengthened together with the functional involvement, the ideological involvement and the emotional involvement to enhance the relevance between tourists and the painting, and ultimately the purpose of the productive protection of the intangible cultural heritage can be realized.

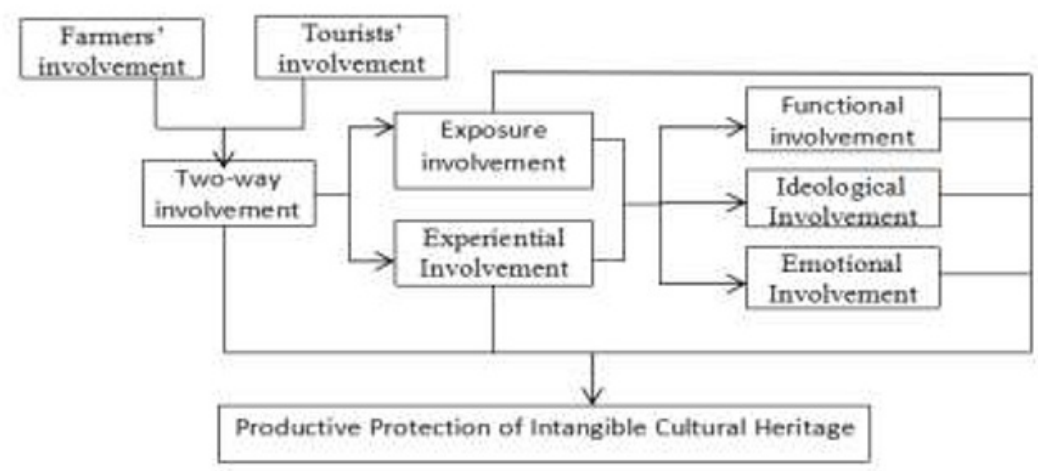

Fig.1: Involvement Analysis on the Productive Protection of In tangible Cultural Heritage

\subsubsection{Two-way Involvement}

Two-way involvement can be said to be the involvement of farmer painters and tourists, it is through the involvement of painters to promote the involvement of tourists, to realize the relationship with tourists from the innovation of artistic characteristics, which means the addition of popular art and innovative design in line with modern popular aesthetics on the basis of maintaining the core skills and core culture of Xinji farmers painting in order to promote the involvement of tourists. 


\subsubsection{Experiential Involvement}

Because the involvement is the expression of the connection intensity between the subject and object, and as the object, Xinji farmers' painting is presented by the hand of the farmers, so it involves the problem of how to strengthen the association between the farmer and the tourists to maximize the bidirectional involvement. Experiential involvement is the key point of this problem, which combines the bidirectional involvement to a certain extent. And this kind of experiential involvement must rely on the rural and farmers field to achieve the effect.

Experiential involvement means that tourists can participate in the production of farmers painting in the field of rural and farmers' land, which can be led by traditional farmer painters, so that they can deepen their understanding of farmer paintings and their relevance to themselves in the process of creating farmer paintings.

\subsubsection{Exposure Type Involvement}

The so-called exposure involvement is based on the "exposure effect", that is, when tourists see or come into contact with something frequently, they will increase their preference for it. This is also an important basis to solve the problem of Xinji farmers' painting dissemination. With the development of new media technology, some farmer painting works with rich artistic characteristics can be collected and distributed to network media platforms by means of pictures, videos and so on to achieve certain exposure and enhance people's understanding of them, but the exposure frequency should not be too high, otherwise it will form a "hyperpolar effect" that too strong stimulation will cause boredom and resentment.

\subsubsection{Functional involvement}

Functional involvement can be achieved by linking the daily lives of modern people and the creation of derivatives. First of all, it should be associated with the daily life of modern people, such as a collection of farmer paintings, some can be displayed in the study, which can express some of the moral of studying hard and reading more; some can be put in the restaurant to express the moral meaning of valuing food; some can be put in the living room to express the moral of family and beauty, and share the moral of harmony. Secondly, the creation of derivatives, Xinji farmers' painting is mostly manifested in the form of paper painting, mural painting at present, so it can be used on other carriers combined with other objects to create popular derivatives.

\subsubsection{Ideological Involvement}

The involvement of ideological thought is the unity of the idea with the modern people's preference of humor and the connotation. Cultural elements and symbols catering to modern interests such as some popular slogans with certain philosophy or or some popular and profound lines in some popular old films can be added to the traditional meaning of the farmers' painting, such as piety, diligence and other positive emotions. Such personalized popular statement is the expression of the current generation, which will bring closer to the distance between the painting works and tourists. 


\subsubsection{Emotional Involvement}

Emotional involvement refers to making people realize the significance of Xinji farmer painting emotionally, which represents the inheritance of human wisdom. Because most of the contents of farmer paintings express positive feelings, they can be combined with the spiritual civilization construction put forward by Chinese government today, such as displaying and publicizing the core values of socialism in the form of farmer paintings. Technically, we can make full use of the environment of the Internet, spread the culture of farmer painting, let people know the farmer painting and its profound historical and cultural connotation, from the emotional recognition.

\section{Conclusion}

At present, although people's living environment and way of life have changed, but we still need traditional culture. However, with the development of the times, most of the intangible cultural heritage such as Xinji farmer painting is facing the situation that the value can not be reflected and can not be sustained. It can not be separated from the fact that tourists can not appreciate some traditional intangible cultural heritage. Therefore, it is necessary to explore productive protection from the perspective of involvement theory, which provides a path for the subsequent protection of intangible cultural heritage. The humanistic value of farmer painting can be easier to be understood and appreciated by more and more people, so that the culture of farmer painting can be sustainable development based on the six strategies proposed in this study.

\section{Acknowledgement}

Thanks are due to the farmer painters of Xinji County interviewed in the study and scholars who made contributions to the study of productive protection and involvement. The study is supported by the Provincial Key Program of Cultural and Artistic Science Planning Project of Hebei Province(Grant No.HB18-ZD011).

\section{References}

Chen Junxiu. (2016). Research on the productive protection and utilization model of intangible cultural heritage.Journal of Guangxi National University(Philosophy and Social Sciences,38(4):64-71.(in Chinese)

Krugman.HE.(1965).The impact of television advertising: Learning without involvement. Public Opinion Quarterly,29:349-356.

Laczniak.RN,Muelhing.DD,Grossbart.S.(1989).Manipulating message involvement in advertising research. Journa lof Advertising, 18(2):28-38.

Liu Qiong.(2012).A probe into the productive protection of handwork intangible cultural heritage : A case sudy of Beijing silk figurine. Cultural Heritage,(4):62-68.(in Chinese)

Liu Qin(2014).The reconstruction of folk custom and the productive protection of Yang Liuqing woodblock new year painting.Art Observation,(10):22-23.(in Chinese)

Ministry of Culture.(2012,February 27).Guidance on strengthening the productive protection of intangible cultural heritage.Chinese Culture Daily, 1.

Palamisamy.R,Wong.SA.(2003).Impact of online consumer characteristics on webbased banner advertising effectiveness.Global Journal ofFlexible System Manageent,4(1/2):15-25. 
Wang Wenzhang. (2006). Introduction to intangible cultural heritage. Beijing: Culture Press.

Wen Xiaoxing.(2017). "Sacred Consumption" and Non-productive Protection of intangible cultural heritage of traditional craftsmanship-Case study of "Hengjiang Zhongzhi" production of Shicheng County of Jiangxi Province. Journal of Northwest Minzu University( Philosophy and Social Science,(4):7-12.(in Chinese)

$\mathrm{Xu}$ Jianghong.(2016).Productive protection of intangible cultural heritage under the path of putting-out purchase: A case study of Miao Batik in Danzhai, Guizhou Province. Guizhou Social Science,(06):88-93.(in Chinese)

Yang Yan(2016).Game and interaction between productive protection and traditional cultural exhibition-Taking the development of Mianzhu New year Painting before and after the earthquake as an example. Sichuan Opera,(04):90-93.(in Chinese)

Zaichkowsky.JI.(1994).The personal involvement inventory: Reduction,revision, and application to advertising. Journal of Advertising,23(4):59-70. 